\title{
Contaminants of Domestic Rural Spring Water Sources in Bushenyi-Ishaka Municipality, Western Uganda
}

\author{
Solomon Adomi Mbina ${ }^{1, ~ *, ~ G a l i m a k a ~ W i l s o n ², ~ E j i k e ~ D a n i e l ~ E z e ~}{ }^{3,4}$, Theophilus Pius², \\ Ssebuufu Robinson ${ }^{5}$, Adam Moyosore Afodun', Iliya Ezekiel ${ }^{7}$ \\ ${ }^{1}$ Department of Public Health, School of Allied Health Sciences, Kampala International University Western Campus, Ishaka, Bushenyi, \\ Uganda \\ ${ }^{2}$ Department of Medical Laboratory Sciences, School of Allied Health Sciences, Kampala International University Western Campus, Ishaka, \\ Bushenyi, Uganda \\ ${ }^{3}$ Department of Physiology, Faculty of Biomedical Sciences, Kampala International University Western Campus, Ishaka, Bushenyi, Uganda \\ ${ }^{4}$ Department of Physiology, School of Medicine, Kabale University, Kabale, Uganda \\ ${ }^{5}$ Faculty of Clinical Medicine and Dentistry, Kampala International University- Teaching Hospital, Ishaka, Bushenyi, Uganda \\ ${ }^{6}$ Department of Anatomy, Faculty of Biomedical Sciences, Kampala International University Western Campus, Ishaka, Bushenyi, Uganda \\ ${ }^{7}$ Department of Biological Sciences, Faculty of Pure and Applied Sciences, Federal University, Wukari, Taraba State, Nigeria
}

\section{Email address:}

mbina.solomon@kiu.ac.ug (S. A. Mbina)

${ }^{*}$ Corresponding author

\section{To cite this article:}

Solomon Adomi Mbina, Galimaka Wilson, Ejike Daniel Eze, Theophilus Pius, Ssebuufu Robinson, Adam Moyosore Afodun, Iliya Ezekiel. Contaminants of Domestic Rural Spring Water Sources in Bushenyi-Ishaka Municipality, Western Uganda. Journal of Health and Environmental Research. Vol. 6, No. 3, 2020, pp. 51-60. doi: 10.11648/j.jher.20200603.12

Received: May 28, 2020; Accepted: June 15, 2020; Published: July 4, 2020

\begin{abstract}
Globally, water-borne diseases have continued to challenge the health conditions of both developed and developing countries. In Uganda, most water-borne diseases are known to be the leading causes of serious health burden among the inhabitants. The study objectives were to characterize microscopic isolates using biochemical tests as well as identify the possible sources of contamination of spring water which is the commonest source of water used by rural inhabitants for domestic activities in Bushenyi-Ishaka Municipality, Bushenyi district, Western Uganda. Samples of spring water were collected from all accessible spring water sources in Bushenyi-Ishaka Municipality, Western Uganda. A total of 48 spring water samples were collected using $500 \mathrm{ml}$ sterile glass bottles. The sources of contamination of the spring water samples were determined using a Sanitary Inspection Checklist which was designed using some standard response factors from a collection of standard reference checklists for drinking water quality assessment. Distribution of isolates and indicator pathogens of fecal contamination recovered from positive samples shows 77.8\% from Nyakabirizi, 75\% from Ishaka and 52.63\% from Central divisions. Among the isolates, Pseudomonas spp and Shigella spp appeared more frequent with overall percentage of (52.63\%) and (45.83\%) whereas, Klebsiella, Staphylococcus aureus and Escherichia coli were found in (31.25\%), (12.5\%) and (6.25\%) respectively. Sanitary inspections showed that springs in Ishaka Division posed a much higher risk $(66.7 \%)$ of bacterial contamination compared to what was observed in Central (58.3\%) and Nyakabirizi (58.3\%) Divisions. All the sampled water sources were contaminated hence they posed substantial risk to users in the communities. Regular water examination and quality control including microbial assessment of all water sources should be maintained in the three Divisions of the Bushenyi-Ishaka Municipality, Western Uganda.
\end{abstract}

Keywords: Bacteriological, Bushenyi, Contamination, Ishaka, Isolates, Municipality

\section{Introduction}

Water is an essential substance to mankind and it influences her social and economic transformations. Cognizant to this fact, access to safe and clean drinking water is human right $[11,12]$. Worldwide, it is estimated that 1.8 billion people do not have access to safe drinking 
water [19, 20]. The number of people accessing essential drinking water and sanitation services worldwide has increased from 315 million in the year 2000 to 700 million in 2017constituting a remarkable progress [7]. However, despite this milestone, $829,000(60 \%)$ diarrhoeal deaths were reported in 2016 due to inadequate water, sanitation and hygiene [8]. The continuous inaccessibility to sufficient and safe water supplies is challenging people globally [14]. The lack of access to sufficient and safe water can lead to dire health consequences and undermine human dignity [10]. In response to the inadequate water supply, majority of people in developing countries like Africa resort to alternative sources of water like boreholes, shallow well, spring, rainwater and deep wells which at most cases are grossly contaminated with water-borne pathogens like protozoan, bacteria and viruses that can cause diarrhea, cholera, typhoid and dysentery [15]. Most water sources for domestic use are contaminated with disease causing pathogens due to leaking or direct dumping of human or animal waste [13]. The main human pathogens which when present in drinking water are capable of transmitting airborne diseases to a majority of the population include Salmonella species, Shigella species, pathogenic Escherichia coli, Vibrio cholerae, Yersinia entercolitica, Campylobacter species, viruses, protozoans and some helminthes [1]. Consequently therefore, stakeholders in water sectors of respective nations are challenged via the Goal number 6 of the Sustainable Development Goals (SDG 6), to 'achieve universal and equitable access to safe and affordable drinking water for all by 2030,' [9]. This can be achieved through regular water quality checks to ascertain the bacterial contaminants (mostly Escherichia coli counts) in various water sources use domestically. Most health challenges and deaths caused by water-borne diseases result from drinking and use of contaminated water for various house whores in low- and middle-income countries. Annually, Africa records about 1.8 million deaths caused by diarrhea due to unsafe water, sanitation and hygiene [2]. It is estimated that $17 \%$ of these deaths in developing countries occurs in children under the age of 5 years [5]. In Uganda, water-borne diseases constitute health burden on the lives of the people especially those in the rural areas who barely can access safe and improved drinking water provided by national supply [6]. Diarrhea disease among children under five years in Uganda has continued to attract public health interest [21]. According to Uganda Demographic Health Survey (UDHS) report, the prevalence of diarrhea in Uganda in the past decade is above $20 \%$ and in daily basis, about 33 children aged 5 years and below die as a result of diarrheal diseases [22]. Most water-borne diseases in Uganda especially in the rural communities are known to have serious health burden on the inhabitants and this can be attributed among other factors to water quality and sources. The main aim of this study therefore was to characterize and identify microscopic isolates as well as identify the possible sources of contamination of spring water used in rural communities in Bushenyi-Ishaka Municipality, Bushenyi District, Western Uganda.

\section{Methodology}

\subsection{Study Design and Geographical Scope}

Bushenyi District is located in Western Uganda. The District lies between $0^{\circ} \mathrm{N}$ and $0^{\circ} 46^{\prime} \mathrm{S}$ of the equator and $29^{\circ} 41^{\prime}$ East and $30^{\circ} 30^{\prime}$ East of Greenwich. The District is bordered by Rubirizi District to the Northwest, Buhweju District to the Northeast, Sheema District to the East, Mitooma District to the South and Rukungiri District to the West. Igara is the main County of Bushenyi District with twelve sub counties, one Municipal Council, three Wards, 64 Parishes and 565 villages. The 2014 census statistics gives the total population size of Bushenyi District as 234,443 [23]. Bushenyi District has a land area of 841 square kilometers and it is 910-2500 meters above sea level. The District headquarters are located in Bushenyi town which is approximately $56 \mathrm{~km}$ on the Mbarara-Ishaka highway West of Mbarara and $6 \mathrm{~km}$ East of Ishaka town. Its coordinates are 00³2'30.0'S 30¹1'16.0'E, latitude -0.541667; longitude 30.18778 [24]. The major economic activities of Bushenyi District are semi intensive agriculture, fishing, trade and commerce, transport, stone quarrying, sand mining, mineral mining, construction industry, tourism and lumbering. The study was analytical involving culturing and biochemical analysis to characterize the various isolates present in sampled spring water. The study was conducted in BushenyiIshaka Municipality in Bushenyi district of Southwestern Uganda. The Bushenyi-Ishaka Municipality comprises of three divisions which include Ishaka Division, Central Division and Nyakabirizi division. The total population of each Division is put at $16,227,16,646$ and 8,190 respectively [23]. The spring water samples were collected from all protected and unprotected spring water sources in the three Divisions of the municipality, Western Uganda.

\subsection{Experimental Procedures}

\subsubsection{Water Sampling Procedure}

The spring water samples were collected from the three Divisions (Ishaka Division, Central Division and Nyakabirizi Division) of Bushenyi-Ishaka Municipality. The water samples were obtained from all accessible spring water sources. These water samples were collected between June and July, 2019. A total of 48 water samples were collected in sterile glass bottles of $500 \mathrm{ml}$ capacity. On collecting the samples, each bottle was labeled and placed in an ice box to maintain a low temperature of about $4{ }^{\circ} \mathrm{C}$ and to prevent multiplication of the microorganisms. The samples were kept in air tight containers during transportation to avoid further contamination. All samples were immediately analyzed as soon they got to the laboratory.

\subsubsection{Total Viable Count (TVC)}

Pour Plate method using plate count agar was used to 
estimate the Total viable count. Serial dilutions $\left(10^{-1}\right.$ to $\left.10^{-10}\right)$ of the water samples were made in sterile $0.85 \%$ normal saline and aliquots of $1 \mathrm{ml}$ were added into every labeled Petri dish. Molten sterilized PCA media cooled to $45^{\circ} \mathrm{C}$ was added into each of the Petri-dishes containing the sample aliquot. The plates were swirled to mix the molten agar with the sample and then agar plates allowed to solidify at room temperature. The inoculated agar plates were then incubated at $37^{\circ} \mathrm{C}$ for $18-24$ hours. All colonies were counted for each dilution plated and the colony forming units per $\mathrm{ml}(\mathrm{CFU} / \mathrm{ml})$ were calculated using standard formula.

$$
c f u / m l=\text { colonycounted } \times \frac{1}{\mathrm{dl}} \times \frac{1}{\operatorname{vol} \text { plated }(\mathrm{ml})}
$$

Discrete colonies formed on PCA were picked and sub cultured on nutrient agar and Mac Conkey agar and isolates were characterized further using biochemical tests after gram staining [4].

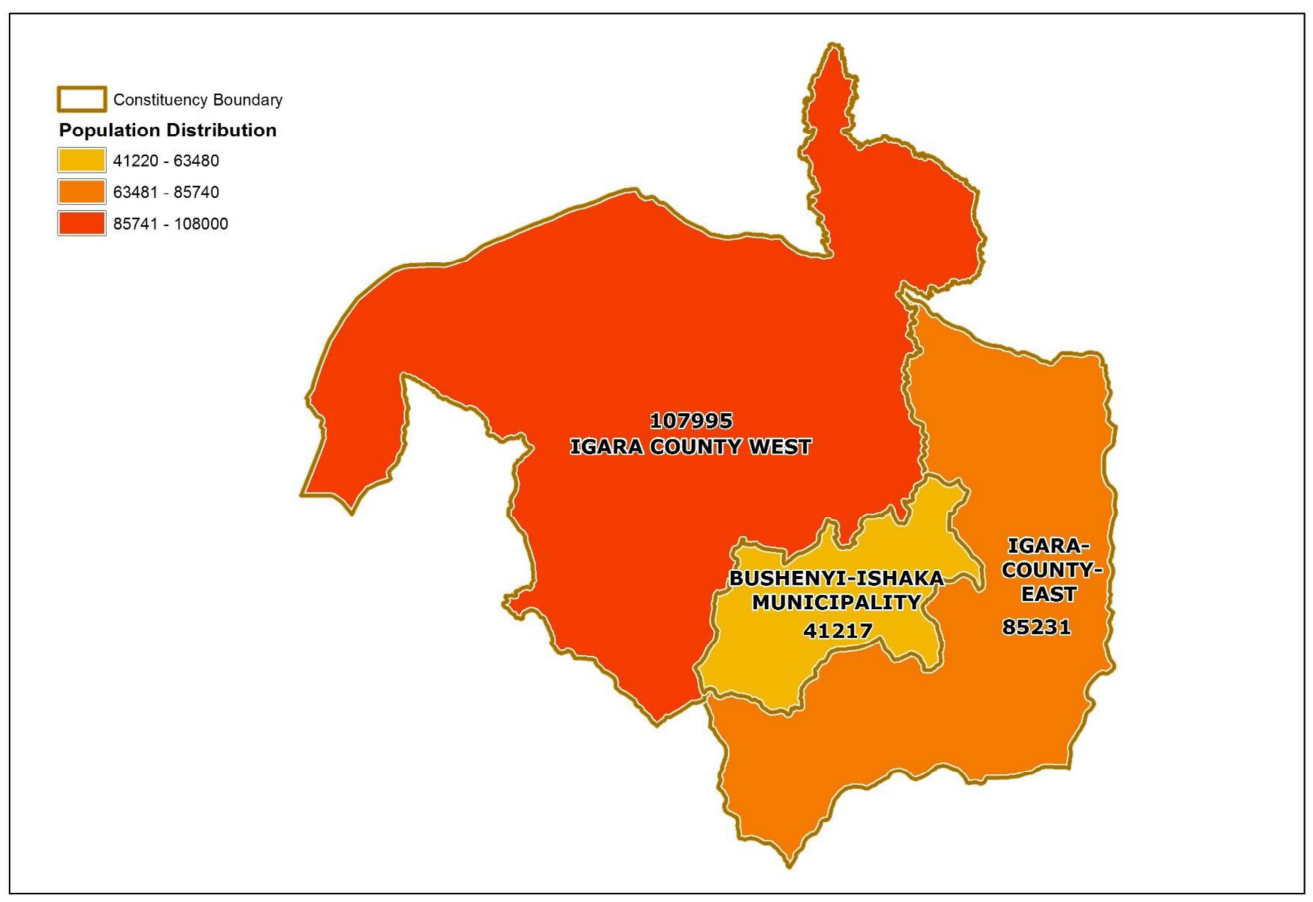

Source: Uganda Bureau of Statistics 2017, The National Population and Housing Census 2014.

Figure 1. Map of Bushenyi District showing the main counties and Bushenyi-Ishaka Municipality, Western Uganda (study area) and their population distribution.

Table 1. Bacteriological standards of drinking water [17].

\begin{tabular}{ll}
\hline Bacteriological Parameters & Standards \\
\hline Total viable counts at $37^{\circ} \mathrm{C}$ (maximum) & $100 \mathrm{CFU} / \mathrm{ml}$ \\
Total Plate Count & $0 \mathrm{CFU} / \mathrm{ml}$ \\
Total Coliform Bacteria & $0 \mathrm{CFU} / \mathrm{ml}$ \\
Total Faecal Coliform Bacteria & $0 \mathrm{CFU} / \mathrm{ml}$ \\
Shigella & $0 \mathrm{CFU} / \mathrm{ml}$ \\
Escherichia coli & $0 \mathrm{CFU} / \mathrm{ml}$ \\
Staphylococcus aureus & $0 \mathrm{CFU} / \mathrm{ml}$ \\
\hline
\end{tabular}

\subsubsection{Phenotypic Characterization of Common Bacterial Contaminants Isolates from Spring Water Samples in Bushenyi-Ishaka Municipality, Western Uganda}

The biochemical tests namely, catalase, oxidase, Simon's citrate, urease, nitrate, sugar fermentation, gas production, $\mathrm{H}_{2} \mathrm{~S}$ production, Indole, Motility, Voges-Prouskauer (VP), Methyl-red (MR) were used to characterize the common bacterial isolates phenotypically as described by [4]

(i). Catalase Test

Catalase enzyme catalyzes the hydrolysis of hydrogen peroxide $\left(\mathrm{H}_{2} \mathrm{O}_{2}\right)$ into oxygen and water. The catalase test was used to identify the presence of catalase enzyme in the test organism. The test was done by introducing a small inoculum into hydrogen peroxide. The presence of the enzyme in a bacterial isolate was evident when a rapid effervescence of oxygen bubbles occurred. This infers a positive test for Staphylococcus aureus.

(ii). Mannitol Salt Agar (MSA) Test

MSA test was used to determine the ability of bacteria to tolerate $7 \%$ salt concentration and ferment mannitol. The results of catalase test informed the MSA test because it serves as a confirmatory test for Staphylococcus aureus. A plate of MSA was inoculated with a discrete colony of the test organism using a sterile wire loop by a streak plate method and incubated at 24-48 hours. The growth and colour of colonies were observed after the incubation period. Tolerant organism showed growth after the incubation period while intolerant organism did not grow. On the other hand, yellow zones around the colonies were an indication of salt tolerant organisms which fermented the mannitol while the salt intolerant organism which did not ferment the mannitol, was identified as the media remained pink.

(iii). Oxidase Test 
This test was used to establish a difference between oxidase negative Enterobacteriaceae and oxidase positive Pseudomadaceae. Cytochrome oxidase detects the presence of an enzyme "oxidase" which is produced by certain bacteria which reduced the dye-tetramethyl-pphenylenediaminedihydrochloride. Freshly emulsified colony of the test organism was transferred in peptone water onto a piece of a new oxidase strip. The strip was then observed for the development of bluish-purple color within 30seconds to 2 minutes. The appearance of bluish/purple color within the set time was considered as a positive reaction. Absence of a color change was inferred as a negative reaction and lack of the enzyme.

\section{(iv). Indole Test}

The Indole test was used to determine the ability of the test organism to split tryptophan molecule into Indole. Indole is one of the metabolites obtained from the degradation of tryptophan. Bacteria that possessed the enzyme tryptophanase are capable of hydrolyzing and deaminating tryptophan with the subsequent production of Indole, pyruvic acid and ammonia. Tryptone broth was inoculated with the test organism and incubated for 18 to 24 hours at $37^{\circ} \mathrm{C}$. Fifteen (15) drops of freshly prepared Kovac's reagent were added down the inner wall of the tube. The development of a bright red color at the interface of the reagent and the broth within seconds showed that Indole was present and the reaction was considered a positive test for Escherichia coli.

(v). Methyl-Red (MR) Test

Methyl-red test is a qualitative test for acid production. This test was conducted to identify the ability of the organism to produce and maintain stable acid end products from glucose fermentation and to overcome the buffering capacity of the system. The MR/VP broth was inoculated with a pure culture of the test organism and incubated at $35^{\circ} \mathrm{c}$ for 48 to 72 hrs. Five drops of MR reagent were then added to the broth. The production of a red ring at the surface of the broth was a positive result for the presence of Escherichia coli.

(vi). Voges-Prouskauer (VP) Test

The VP test was used to determine the ability of the test organisms to produce neutral end product acetyl-methyl carbinol (acetoin) from glucose fermentation. Pure culture of the test organism was inoculated into MR/VP broth and incubated for 24 hours at $35-37^{\circ} \mathrm{C}$. To the aliquot of $1 \mathrm{ml}$ of the broth in a sterile test tube, $0.6 \mathrm{ml}$ of VP (A) was added followed by $0.2 \mathrm{ml}$ of VP (B). The tube was then gently shaken to expose the medium to atmospheric oxygen after which it was allowed to remain undisturbed for 10 to 15 minutes. The development of a pinkish red color at the surface of the medium was a positive result for Klebsiella spp. whereas the presence of a yellow colour at the surface of the medium was a negative result.

(vii). Simon's Citrate Test

The Simon's Citrate test was used to identify enterobacteria. The ability of an organism to use citrate as its sole source of carbon and ammonia as its only source of nitrogen was determined using the Simon's citrate test. The test was conducted by streaking the inoculum over the slant of
Simon's citrate agar in a tube and incubated for 24-48 hours at $35-37^{\circ} \mathrm{C}$. A positive result for Klebsiella spp was the presence of growth on the slant and bluish colored medium while a greenish colored medium was negative result.

(viii). Urease Test

The ability of bacteria to hydrolyze urea to ammonia using the urease enzyme was determined by Urease test. Urea broth (yellow-orange color) was inoculated with sterile inoculating wire loop and observed for color change. In the presence of ammonia, the urea broth turned bright pink signifying a positive test for Proteous spp and Klebsiella spp.

A negative test showed the broth remaining yellow-orange indicating no ammonia was produced hence Escherichia coli was absent.

(ix). Triple Sugar Iron (TSI) Agar

Triple Sugar Iron (TSI) agar is a composite medium used to study different properties of bacteria (such as Gram negative) for sugar fermentation, gas production and hydrogen sulphide $\left(\mathrm{H}_{2} \mathrm{~S}\right)$ production. Phenol red and ferrous sulphate served as indicators of acidification and $\mathrm{H}_{2} \mathrm{~S}$ formation, respectively. The formation of $\mathrm{CO}_{2}$ was indicated by the presence of bubbles or cracks in the agar or by separation of the agar from the sides or bottom of the tube. The production of $\mathrm{H}_{2} \mathrm{~S}$ required an acidic environment and was indicated by blackening of the butt of the medium in the tube. The test was done by touching a well isolated colony of the test organism with a sterile straight wire loop and inoculating TSI by first stabbing through center of the medium to the bottom of the tube and then streaking the surface of the agar slant. The cap was left loosely and the tube incubated for 18-24 hours at $35^{\circ} \mathrm{C}$ in an incubator. Alkaline slant/no change in the butt $(\mathrm{K} / \mathrm{K})$, indicated glucose, lactose and sucrose non-utilizer like Pseudomonas spp (alkaline slant/alkaline butt), Acid slant/acid butt (A/A), with gas production indicated glucose, sucrose, and/or lactose fermenter like Escherichia coli. Alkaline slant/acid butt (K/A), $\mathrm{H}_{2} \mathrm{~S}$ production meant glucose fermentation only by Salmonella typhi.

\section{(x). Motility Test}

Motility test was used to differentiate between the motile and non-motile bacteria species. The test was conducted by stabbing motility media with a sterile wire loop and the media inoculated at $37^{\circ} \mathrm{C}$ for $18-24$ hours. A feather-like growth observed moving away from the stab line signified a mobile bacterium and a positive test for bacteria such as Escherichia coli. The growth along stab line indicated non-motile bacteria such as Shigella.

\subsection{Potential Factors/Sources of Contamination of Spring Water in Bushenyi-Ishaka Municipality, Western Uganda}

The assessment of the potential sources of contamination of spring water sources in the three division of the municipality was determined using a Sanitary Inspection Checklist (SIC) designed from a collection of standard reference checklists for drinking water quality assessment. 


\section{Results}

\subsection{Determination of Total Plate (Viable) Counts}

The analysis of spring water samples collected from the three Divisions of Bushenyi-Ishaka Municipality indicates that all the water samples had observable viable counts. The results are presented in table 2 below.

Table 2. Total Viable Counts in spring water samples in Bushenyi-Ishaka municipality, Western Uganda.

\begin{tabular}{lll}
\hline Sample site & $\begin{array}{l}\text { Sample size (number } \\
\text { of sampled springs) }\end{array}$ & Range CFU/ml \\
\hline Ishaka & 24 & $4000-5.61 \times 10^{5}$ \\
Central & 10 & $37000-4.70 \times 10^{5}$ \\
Nyakabirizi & 14 & $24000-6.07 \times 10^{5}$ \\
\hline
\end{tabular}

The highest total viable count was obtained from Nyakabirizi Division with aerobic counts that ranged from
$24000-6.07 \times 10^{5} \mathrm{cfu} / \mathrm{ml}$. This was followed by Ishaka Division with viable counts of over $5.61 \times 10^{5} \mathrm{cfu} / \mathrm{ml}$ then Central Division with viable counts of $37000-4.70 \times 10^{5}$ $\mathrm{cfu} / \mathrm{ml}$. All the observed microbial contaminants ranges were above WHO reference standards for drinking water as shown in table 1.

Microscopic examination of Gram reaction of cultured water samples in Bushenyi-Ishaka Municipality

The microscopic examination of Gram reaction was aimed at determining the morphology of the bacteria in order to classify them into Gram Positive cocci (GPC) and Gram Negative Rod (GNR). The Gram staining further gave an insight on the best biochemical test to use in identifying the bacteria present in the water samples collected. The Gram Positive appeared purple while the Gram Negative appeared pink in colour. The results of these reactions are given in tables 3, 4 \& 5 below.

Table 3. Gram's reaction of colonies of cultured water samples collected from Ishaka Division, Bushenyi-Ishaka Municipality, Western Uganda.

\begin{tabular}{|c|c|c|c|c|c|}
\hline \multirow{2}{*}{ Serial number of water sample } & \multicolumn{2}{|c|}{ Gram's Reaction } & \multirow{2}{*}{ Serial number of water sample } & \multicolumn{2}{|c|}{ Gram's Reaction } \\
\hline & GNR & GPC & & GNR & GPC \\
\hline 1 & + & - & 13 & + & - \\
\hline 2 & + & - & 14 & + & - \\
\hline 3 & + & - & 15 & + & - \\
\hline 4 & + & - & 16 & + & - \\
\hline 5 & + & - & 17 & + & - \\
\hline 6 & + & - & 18 & + & - \\
\hline 7 & + & - & 19 & + & - \\
\hline 8 & + & - & 20 & + & - \\
\hline 9 & + & + & 21 & + & - \\
\hline 10 & + & - & 22 & + & - \\
\hline 11 & + & - & 23 & + & - \\
\hline 12 & + & - & 24 & + & - \\
\hline
\end{tabular}

Key: GNR=Gram Negative Rod (Escherichia coli, Pseudomonas spp and Klebsiella spp).

$\mathrm{GPC}=$ Gram Positive cocci (Staphylococcus aureus. Shigella spp and streptococcus spp.).

Twenty four (24) spring water samples were collected from Ishaka Division. After the staining reaction, all the twenty-four samples had GNR except the sample with serial number 9 which contains both GNR and GPC.

Table 4. Gram's reaction of colonies of cultured water samples collected from Central Division, Bushenyi Municipality, Western Uganda.

\begin{tabular}{|c|c|c|c|c|c|}
\hline \multirow{2}{*}{ Serial number of water sample } & \multicolumn{2}{|c|}{ Gram's Reaction } & \multirow{2}{*}{ Serial number of water sample } & \multicolumn{2}{|c|}{ Gram's Reaction } \\
\hline & GNR & GPC & & GNR & GPC \\
\hline 1 & + & - & 6 & + & - \\
\hline 2 & + & + & 7 & + & + \\
\hline 3 & + & - & 8 & + & - \\
\hline 4 & + & + & 9 & + & - \\
\hline 5 & + & - & 10 & + & + \\
\hline
\end{tabular}

Key: GNR=Gram Negative Rod (Escherichia coli, Pseudomonas spp and Klebsiella spp)

GPC $=$ Gram Positive cocci (Staphylococcus aureus. Shigella spp and streptococcus spp.)

The overall result of the ten water samples collected from Central Division indicates that six samples had only GNR while four samples with serial numbers (2, 4, 7 and 10) had both GNR and GPC.

Table 5. Gram's reaction of colonies of cultured water samples collected from Nyakabirizi Division, Bushenyi Municipality, Western Uganda.

\begin{tabular}{lllll}
\hline \multirow{2}{*}{ Serial number of water sample } & Gram's Reaction & & \multirow{2}{*}{ Serial number of water sample } & Gram's Reaction \\
\cline { 2 - 5 } & GNR & GPC & GNR & GPC \\
\hline 1 & + & - & 8 & + \\
2 & + & - & 9 & + \\
3 & + & - & 10 & + \\
4 & + & - & 12 & + \\
5 & + & - & - & + \\
\hline
\end{tabular}




\begin{tabular}{lllllll}
\hline \multirow{2}{*}{ Serial number of water sample } & Gram's Reaction & \multirow{2}{*}{ Serial number of water sample } & \multicolumn{2}{c}{ Gram's Reaction } \\
\cline { 2 - 5 } & GNR & GPC & GNR & GPC \\
\hline 6 & + & - & 13 & + & + \\
7 & + & - & 14 & + & - \\
\hline
\end{tabular}

Key: GNR=Gram Negative Rod (Escherichia coli, Pseudomonas spp and Klebsiella spp).

GPC $=$ Gram Positive cocci (Staphylococcus aureus. Shigella spp and Streptococcus spp.).

Fourteen (14) water samples were analyzed from Nyakabirizi Division; the results show that only one sample with serial number 13 had both GNR and GPC. This implies that all the water samples collected were contaminated by one form of bacteria or the other.

\subsection{Biochemical Test}

The biochemical characterization of the possible bacteria in the collected spring water samples indicated the presence Pseudomonas spp, Shigella spp, Escherichia coli, Klebsiella spp. and Staphylococcus aureus. Results are shown in table 6 below.

Table 6. Biochemical characterization of Isolates in water samples collected from different spring water sources in Bushenyi-Ishaka-Municipality Divisions.

\begin{tabular}{|c|c|c|c|c|c|}
\hline \multirow{2}{*}{ Biochemical Test } & \multicolumn{5}{|c|}{ Organisms } \\
\hline & E. coli & Klebsiella & Shigella & Pseudomonas & S. aureus \\
\hline Catalase & - & - & - & + & + \\
\hline Manital & - & - & - & _ & + \\
\hline Motility & $\overline{+}$ & + & - & + & _- \\
\hline Methyl-red & + & + & + & & - \\
\hline Voges-Proskauer & & & & - & + \\
\hline Indole & + & - & $\overline{ \pm}$ & - & _- \\
\hline Oxidase & _ & - & _- & + & - \\
\hline Citrate & - & + & + & + & - \\
\hline Urease & - & + & _- & _- & $\overline{+}$ \\
\hline Lactose fermentation & AG & AG & - & - & _- \\
\hline Glucose fermentation & AG & AG & A & _- & A \\
\hline Sucrose fermentation & $\mathrm{A} \pm$ & _- & $\mathrm{A} \pm$ & - & A \\
\hline $\mathrm{H}_{2} \mathrm{~S}$ Gas & & - & & & \\
\hline
\end{tabular}

Key: $E$. coli=Escherichia coli, $S$. aureus $=$ Staphylococcus aureus, $\mathrm{H}_{2} \mathrm{~S}=$ Hydrogen sulphide, $\mathrm{A}=$ Acid production, $\mathrm{AG}=\mathrm{Acid}$ and gas production, $\pm=$ Variable reaction, $+=$ Positive, $-=$ Negative.

The major microbial isolates identified in the spring water samples using the biochemical tests shows that Pseudomonas and Staphylococcus aureus were positive to catalase test in most water samples and only Staphylococcus aureus was positive to mannitol test. Escherichia coli, Klebsiella spp and Pseudomonas spp were the motile bacteria identified and were also positive for methyl red test except Pseudomonas spp. Only Staphylococcus aureus and Pseudomonas spp were positive for Voges-Proskauer and oxidase tests respectively. Shigella spp, Klebsiella spp and Pseudomonas spp were prominent as indicated in citrate test while only Klebsiella spp and Staphylococcus aureus were indicated in urease test. The main triple sugar (glucose, lactose and sucrose) fermenter identified in the water samples was Escherichia coli. While Klebsiella spp fermented only lactose and glucose. Escherichia coli, Klebsiella spp, Shigella spp and Staphylococcus aureus were positive to glucose fermentation while Escherichia coli, Shigella spp and Staphylococcus aureus were positive to sucrose fermentation. Salmonella spp and vibrio spp were absent in the water samples as no $\mathrm{H}_{2} \mathrm{~S}$ gas was produced.

\subsection{Potential Sources of Contamination of Spring Water Sources in Bushenyi-Ishaka Municipality, Western Uganda}

Twelve standard response factors were used to assess the potential sources of contamination in the forty eight (48) spring water points where water samples were collected. Details of the results are presented in table 7 below.

Table 7. Assessment of potential sources/factors of spring water contamination in Bushenyi-Ishaka Municipality, Western Uganda.

\begin{tabular}{|c|c|c|c|c|c|}
\hline & \multirow{2}{*}{ Variable response factors } & \multirow{2}{*}{$\begin{array}{l}\text { Response } \\
\text { options }\end{array}$} & \multicolumn{3}{|c|}{ Water sample sourceIshaka Central Nyakabirizi } \\
\hline & & & $(n=24)$ & $(n=10)$ & $(n=14)$ \\
\hline \multirow{3}{*}{1} & \multirow{2}{*}{ Spring type protected } & YES & $23(95.85)$ & $10(100 \%)$ & $14(100 \%)$ \\
\hline & & NO & $1(4.2 \%)$ & $0(0 \%)$ & $0(0 \%)$ \\
\hline & \multirow{2}{*}{ Spring fenced } & YES & $1(4.2 \%)$ & $0(0 \%)$ & $0(0 \%)$ \\
\hline 2 & & NO & $23(95.85)$ & $10(100 \%)$ & $14(100 \%)$ \\
\hline \multirow[b]{2}{*}{3} & \multirow{2}{*}{ Presence of cracks or dirty drainage channels } & YES & $9(37.5 \%)$ & $8(80 \%)$ & $7(50 \%)$ \\
\hline & & NO & $15(62.5 \%)$ & $2(20 \%)$ & $7(50 \%)$ \\
\hline \multirow{2}{*}{4} & \multirow{2}{*}{ Presence of toilets around the water source } & YES & $2(14.3 \%)$ & $0(0 \%)$ & $1(7.14 \%)$ \\
\hline & & NO & $22(91.6 \%)$ & $10(100 \%)$ & $13(92.8 \%)$ \\
\hline \multirow{2}{*}{5} & \multirow{2}{*}{ Distance of toilets from water source } & YES (far) & $23(95.85)$ & $9(90 \%)$ & $13(92.8 \%)$ \\
\hline & & NO (close) & $1(4.2 \%)$ & $1(10 \%)$ & $1(7.14 \%)$ \\
\hline
\end{tabular}




\begin{tabular}{|c|c|c|c|c|c|}
\hline & \multirow{2}{*}{ Variable response factors } & \multirow{2}{*}{$\begin{array}{l}\begin{array}{l}\text { Response } \\
\text { options }\end{array} \\
\end{array}$} & \multicolumn{3}{|c|}{ Water sample sourceIshaka Central Nyakabirizi } \\
\hline & & & $(\mathrm{n}=\mathbf{2 4})$ & $(n=10)$ & $(n=14)$ \\
\hline \multirow{2}{*}{6} & \multirow{2}{*}{ Water point } & YES (AH) & $1(4.2 \%)$ & $10(100 \%)$ & $1(7.14 \%)$ \\
\hline & & $\mathrm{NO}(\mathrm{DH})$ & $23(95.85)$ & $0(0 \%)$ & $13(92.8 \%)$ \\
\hline \multirow{2}{*}{7} & \multirow{2}{*}{ Water point clean } & YES & $11(45.8 \%)$ & $1(10 \%)$ & $6(42.8 \%)$ \\
\hline & & NO & $13(54.2 \%)$ & $9(90 \%)$ & $8(57.1 \%)$ \\
\hline \multirow{2}{*}{8} & \multirow{2}{*}{ Water containers clean } & YES & $9(37.5 \%)$ & $2(20 \%)$ & $3(78 \%)$ \\
\hline & & NO & $15(62.5 \%)$ & $8(80 \%)$ & $11(78.6 \%)$ \\
\hline \multirow{2}{*}{9} & \multirow{2}{*}{$\begin{array}{l}\text { Do people wash their legs, clothes, containers at the water } \\
\text { point }\end{array}$} & YES & $9(37.5 \%)$ & $4(40 \%)$ & $10(71.42 \%)$ \\
\hline & & NO & $15(62.5 \%)$ & $6(60 \%)$ & $4(28.6 \%)$ \\
\hline \multirow{2}{*}{10} & \multirow{2}{*}{$\begin{array}{l}\text { Is there any other pollutant source within } 10 \mathrm{~m} \text { from the } \\
\text { unprotected source }\end{array}$} & YES & $3(12.5 \%)$ & $2(20 \%)$ & $2(14.3 \%)$ \\
\hline & & NO & $21(87.5 \%)$ & $8(80 \%)$ & $12(85.7 \%)$ \\
\hline \multirow{2}{*}{11} & \multirow{2}{*}{ Is there any stream channel flowing near the water source } & YES & $5(20.8 \%)$ & $1(10 \%)$ & $1(7.14 \%)$ \\
\hline & & NO & $19(79.2 \%)$ & $9(90 \%)$ & $13(92.14 \%)$ \\
\hline \multirow{2}{*}{12} & \multirow{2}{*}{ Do animals have access to spring in radius $10 \mathrm{~m}$} & YES & $19(79.2 \%)$ & $8(80 \%)$ & $11(78.6 \%)$ \\
\hline & & NO & $5(20.83 \%)$ & $2(20 \%)$ & $3(21.42 \%)$ \\
\hline
\end{tabular}

AH=Above hill; $\mathrm{DH}=$ Down hill.

The results obtained after collecting data with the inspection checklist shows that although proper sanitation was kept around various water points and toilets were located far from the water sources, but all the forty-eight spring water sources still faced some risks of contamination with bacterial fecal organisms in all the three divisions. The results indicates that the main sources of contamination of the springs in the three divisions were absence of a Perimeter fence, presence of cracks or dirty drainage channels, location of water points downhill which exposed the water to washed wastes and contaminants, dirty unclean water collection containers used by the people to fetch water for drinking and domestic use and washing of legs, clothes and containers around the water points by the people.

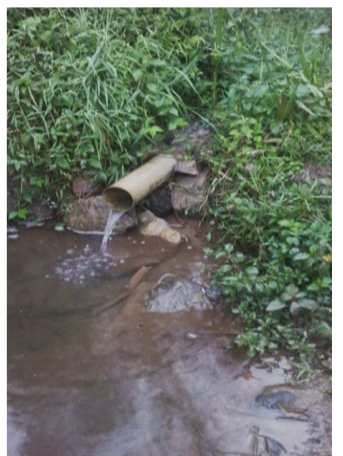

Figure 2. Protected water point without a perimeter fence in Central Division.

Some of the water points were channeled with a plastic pipe to direct the flow and easy collection of the water by the inhabitants (figures $2,4 \& 5$ ) while some were not channeled with a pipe (figure 3 ). Some water collection points had no protection against man, animal, agricultural and bacterial activities/wastes which may be washed or dumped into the water (figures $2 \& 3$ ). Most of the water collection points were protected with perimeter fence/wall and the water was properly channeled with a pipe but the surrounding was still exposed to contaminants like organic waste, wrappers, debris and animal matter (figure 4). Human activities like washing of clothes, legs and other items were also observed in some water collection points. (Figure 5).

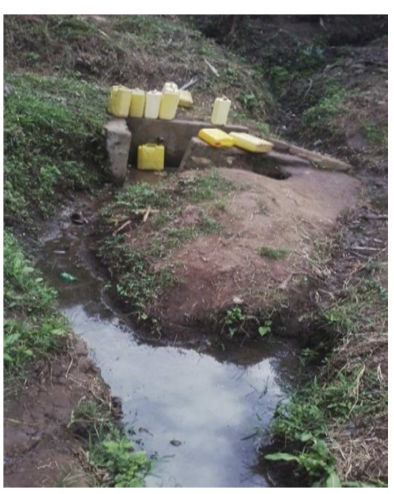

Figure 3. Unprotected spring water point in Ishaka Division.

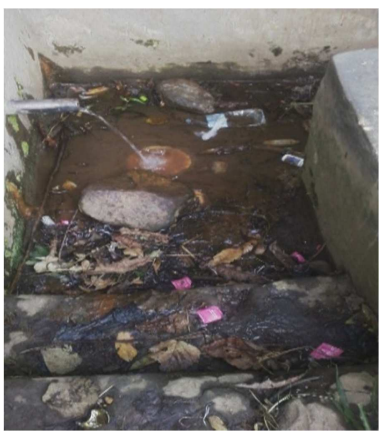

Figure 4. Protected spring water point showing potential sources of water contamination.

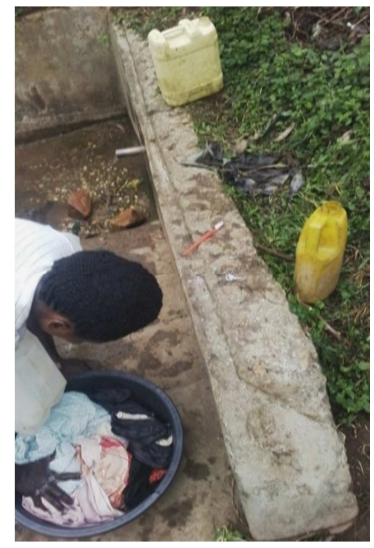

Figure 5. Protected water point with perimeter fence in Nyakabirizi division. 


\section{Discussions}

In this study, the highest total viable counts (TVC) obtained ranged from $24000-6.07 \times 10^{5} \mathrm{cfu} / \mathrm{ml}$ in Nyakabirizi Division to over $5.61 \times 10^{5} \mathrm{cfu} / \mathrm{ml}$ counts in Ishaka Division and 37000 $4.70 \times 10^{5} \mathrm{cfu} / \mathrm{ml}$ in Central Division (table 2). These results were higher when compared with the standard reference ranges [17] for drinking water (table 1). The implication therefore is that most of the spring water sources in Bushenyi-Ishaka Municipality were contaminated with bacteria which pose a major public health problem. The morphological classification of bacteria in the spring water samples analyzed shows that all the water samples in Ishaka Division had GNR or both GNR and GPC (table 3), in Central Division six samples had only GNR and four had both GNR and GPC (table 4) and in Nyakabirizi Division, all the water samples had GNR or both GNR and GPC (table 5). The predominant bacteria identified in the spring water samples after the biochemical tests were Pseudomonas spp, Shigella spp, Escherichia coli, Klebsiella spp and Staphylococcus aureus while Salmonella typhi and vibrio spp were absent (table 6). This result agrees with a similar study conducted by [6], which reported the absence of Salmonella spp in all spring water samples examined. The number of Escherichia coli present in the water samples, was found to be $6.25 \%$. This result differs from the $35.6 \%$ number of Escherichia coli reported by Bhagra, (2017) in sub Himalayan region [3]. The low prevalence of Escherichia coli in the spring water samples might be attributed to variation in season and the geographical protection of the springs from human and animal wastes. This study was conducted in dry season (June-July, 2019) period in Uganda; hence the underground leakage may be less compared to rainy season. In addition, the location of most of the springs accessed were under the stones which directs their flow through a narrow outlet thereby reducing the high probability of contamination by human or animal activities. The absence of any Salmonella spp in all of the water samples examined in this study cannot qualify the spring water sources' safety. Primarily, studies had proven that $E$. coli was a much better indicator of disease risk assessment [25]. The presence of Escherichia coli in the water samples therefore is a better fecal indicator hence positive indication of fecal water contamination.

Findings of this study indicates that out of the forty-eight analyzed spring water samples, $46(95.8 \%)$ were protected with a concrete box fitted with a metallic pipe that led water directly into a collection vessel, only 2 (4.2\%) were unprotected, $1(2.15 \%)$ had a fence as an enclosure surrounding the water point that protected animals from accessing the water point. The remaining 47 (97.925\%) were without a fence (table 7, figures 1 and 2). Majority 46 (95.8\%) of the springs were located downhill where cattle rearing and other agricultural activities takes place (table 7). Most 41 $(85.42 \%)$ of the springs water sources were located near valleys which human activities like washing of clothes, bathing as well as grazing by animals constitute sources of contamination (table 7 and figure 4). Generally, the main sources of contamination of the springs in the three divisions of Bushenyi-Ishaka Municipality discovered by this study were absence of a Perimeter fence, presence of cracks or dirty drainage channels, location of springs downhill, dirty water point, dirty water collection containers, washing of legs, clothes and containers around the water point. This finding is similar study conducted by [26] which confirms that environment chemicals, human and animal faeces are sources of contamination, and may result in illnesses and diseases in human body. This situation therefore continues to expose inhabitants to high risk health problems, particularly, to the serious outbreaks of diarrheal disease which is commonly reported in the study area.

\section{Conclusions and Recommendation}

Most of the springs which rural inhabitants in Bushenyi Ishaka Municipality, Western Uganda rely as their alternative source of domestic and drinking water are polluted by microbial contaminants due to one source of contamination or the other. The prominent microbial contaminants found were Pseudomonas spp, Shigella spp, Klebsiella spp, Staphyllococcus aureus and Escherichia coli. The presence of Coliform bacteria and Escherichia coli in the water samples is therefore an indicator of fecal contamination. These contaminations are mostly as a result of lack of were perimeter fence around some water points, presence of cracks or dirty drainage channels, location of springs/ water points downhill, untidy water point and surroundings, constant presence of human activities like washing of legs, clothes and other items around the water points. Regular bacteriological assessment of all spring water sources as well erecting of perimeter wall/fence around all water points in the area in order to prevent animal droppings, debris, run-off water and other forms of anthropogenic sources of contamination is highly recommended.

\section{Availability of Data and Materials}

The datasets used during this study can be obtained from the corresponding author on request.

\section{Author's Contribution}

All authors had equal contributions to this research work. SAM and GW designed the study; SAM, GW, TP collected the water samples. SAM, GW, TP, EDE, SR, AMA and IE conducted the analysis and interpretation of the data. SAM, EDE, GW, TP, SR, AMA and IE studied the interpreted data, prepared the initial manuscript and approved it for publication.

\section{Ethics Approval and Consent to Participate}

Ethical approval for the study was obtained from the Kampala International University-Research and Ethics 
Committee, Western Campus, Uganda. The access to the community for water sample collection from the various Divisions for analysis was granted by the District Health Officer (DHO) of Bushenyi District.

\section{Competing Interests}

The authors declare that they have no competing interests.

\section{Acknowledgements}

The authors would like to acknowledge the support rendered by the staff and management of the Kampala International University-Teaching Hospital, Western Campus, Ishaka, Uganda whose equipped Pathology and Microbiology Laboratories were used for storage and analysis of the water samples. The authors will also wish to appreciate the Bushenyi District authority for their permission to access the community and spring water sources or points for samples collection as well sharing of primary information which were important to the study. The authors are also grateful to the community focal persons and leaders who were ever present to direct the authors to the sources of the spring water in the various Divisions.

\section{References}

[1] Adaro, I. Y., James, N. G., Ndung, P., \& Ohanu, M. E. Bacteriological Quality Assessment of Bottled Water Brands Marketed in Kitale Town, Trans - Nzoia County, Kenya. Journal of Advances in Microbiology 2017, 2: 1-9.

[2] Adegalu, A., Emmanuel, A., Awokunmi, E., Odunayo, R., \& Edward, A. Physicochemical and bacteriological assessment of hand-dug wells water from Ile-oluji, Nigeria (2016), 433-440.

[3] Bhagra, S., Singh, D., Sood, A., \& Kanga, A. Bacteriological profile of water samples in and around Shimla hills : A Study from the Sub Himalayan Region. International Journal of Community Medicine and Public Health International Journal of Community Medicine2017 4: 1966-1971.

[4] Cheesbrough, M. District laboratory practice in tropical countries (Second Edn). Cambridge university press, 2005.

[5] Edessa, N., Geritu, N., \& Mulugeta, K. (2017). Microbiological assessment of drinking water with reference to diarrheagenic bacterial pathogens in Shashemane Rural District, Ethiopia. African Journal of Microbiology Research 2017, 11: 254-263.

[6] Yasin, M., Ketema, T., \& Bacha, K. Physico-chemical and bacteriological quality of drinking water of different sources, Jimma zone, Southwest Ethiopia. BMC Research Notes, 2015, 8: $1-13$.

[7] WHO/UNICEF Joint Monitoring Programme. Progress on Household Drinking Water, Sanitation and Hygiene 20002017. (United Nations Children's Fund and World Health Organization, New York, 2019.

[8] Pruss-Ustun, A., Jennyfer, Wolf., Jamie, Bartram, Thomas, Clasen, Oliver, Cumming, Mathew, C..... Richard Johnston.
Burden of disease from inadequate water, sanitation and hygiene for selected adverse health outcomes: an updated analysis with a focus on low- and middle-income countries. International Journal of Hygiene and Environmental Health 2019, 222: 765-777.

[9] United Nations: Report of the Inter-Agency and Expert Group on Sustainable Development Goal Indicators. New York/Geneva. 2016.

[10] Watkins K: Human Development Report - Beyond scarcity: Power, poverty and the global water crisis 2006.

[11] WHO. Guidelines for drinking-water quality. World Health Organization 2011.

[12] Bloomfield SF. The chain of infection transmission in the home and everyday life settings, and the role of hygiene in reducing the risk of infection 2012, Simmons College, Boston, MA USA.

[13] Nafi'u A, Anandapandian K. T. K: The Occurrence of Waterborne Diseases in Drinking Water in Nakaloke SubCounty, Mbale District, Uganda. International Journal of Science and Research (IJSR) 2016, 5: 1416-1421.

[14] Dick SM., Handzel T, Venczel L: Chlorination and Safe Storage of Household Drinking Water in Developing Countries to Reduce Waterborne Disease. Journal of Water Science and Technology 2003, 47: 221-228.

[15] Nygard K: Water and Infection Epidemiological Studies of Epidemic and Endemic Waterborne Diseases. Masters Dissertation, Norwegian Institute of Public Health 2008, 11-20.

[16] World Health Organization and United Nation International Children Emergency Funds Joint Monitoring Programme. World Health Organisation Press 2012, 1.

[17] WHO. Guidelines for Drinking Water Quality, Vol. 3: Surveillance and Control of Community Water Supplies. 2nd Edition, World Health Organisation, Geneva 1997.

[18] UNICEF. Progress for Every Child in the SDG Era. wwwdatauniceforg. UNICEF, New York, NY 2018.

[19] Bain R, Cronk R, Hossain R, Bonjour S, OndaK, Wright J, YangH, Slaymaker T., Hunter P, Prüss-Ustün A: Global assessment of exposure to faecal contamination through drinking water based on a systematic review 2014.

[20] Onda K., LoBuglio J. \& Bartram J. Global access to safe water: accounting for water quality and the resulting impact on MDG progress. International Journal of Environmental Research and Public Health2012, 9: 880-894.

[21] Ssenyonga R., Muwonge R., Twebaze F. \& Mutyabule R. Determinants of acute 0-5 years in Uganda. East African Medical Journal 2009, 86: 513-519.

[22] Uganda Demographic Health Survey (UDHS): Uganda Demographic and Health Survey. Uganda Bureau of Statistics, Kampala, Uganda 2011.

[23] Uganda Bureau of Statistics (UBOS) and ICF: Uganda Demographic and HealthSurvey 2016: key indicators Report. Kampala, Uganda and Rockville, Maryland, USA. 2017.

[24] Globefeed. Com: Distance between Dominion church, Bushenyi Western Region, Uganda and Caltex Petrol Station, Ntungamo-Katunguru Road, Ishaka, Western Region, Uganda. Globefeed.com (GFC). 2016. 
[25] EPA: Report of Task Force on Guide Standard and Protocol for Testing Microbiological Water Purifiers. United States Environmental Protection Agency, CI, 1986, 1-29.
[26] Fasunwon O, OlowofelaJ, Akinyemi O, Fasunwon B, Akintokun O: Contaminants Evaluation as Water Quality Indicator in Ago-Iwoye, South-western, Nigeria African Physical Review (2008) 2: 0012. 